\title{
Understanding the problem of access to public health insurance schemes among cross-border migrants in Thailand through systems thinking
}

Watinee Kunpeuk ( $\nabla$ watinee@ihpp.thaigov.net )

International Health Policy Program https://orcid.org/0000-0001-8670-0806

\section{Pard Teekasap}

Stamford University

\section{Hathairat Kosiyaporn}

International Health Policy Program, Ministry of Public Health

\section{Sataporn Julchoo}

International Health Policy Program, Ministry of Public Health

\section{Mathudara Phaiyarom}

International Health Policy Program, Ministry of Public Health

\section{Pigunkaew Srinam}

International Health Policy Program, Ministry of Public Health

\section{Nareerut Pudpong}

International Health Policy Program, Ministry of Public Health

\section{Rapeepong Suphanchaimat}

International Health Policy Program; Bureau of Epidemiology, Department of Disease Control, Ministry of Public Health

\section{Research article}

Keywords: Systems thinking, migrants, health insurance, health policy

Posted Date: March 20th, 2020

DOl: https://doi.org/10.21203/rs.3.rs-18157/v1

License: (c) (i) This work is licensed under a Creative Commons Attribution 4.0 International License. Read Full License

Version of Record: A version of this preprint was published at International Journal of Environmental Research and Public Health on July 15th, 2020. See the published version at https://doi.org/10.3390/ijerph17145113. 


\section{Abstract}

Background The migrant health agenda in Thailand has been shaped by domestic and international pressures relating to social and economic dimensions. Thailand has become a popular destination for international migrant workers particularly from Cambodia, Lao PDR, and Myanmar. However, only a fraction of these migrant workers were insured by public health insurance. This study aimed to apply systems thinking to explore contextual factors affecting access to public health insurance arrangements among cross-border migrants in Thailand.

Methods A group model building (GMB) was applied to explore contextual factors and their interplay influencing access to health insurance for migrants in Thailand. Participants $(n=20)$ were encouraged to share ideas about underlying drivers and barriers of access to health insurance among migrants. Triangulation was performed with the document review. The findings were analysed by a thematic approach. The causal loop diagramme (CLD) and stock and flow diagramme (SFD) were synthesised to identify the dynamics relating to access to migrant health insurance.

Results Nationality verification was recognised as one of the most important mechanisms that the Thai government exercises to deal with the precarious citizenship status of undocumented migrants. Also, it is the key function that links economic necessity, national security, and public health concerns. In the formal sector, the government plays an important role in the enrollment of migrant workers in the Social Security Scheme (SSS) run by the Ministry of Labour (MOL). In the informal sector, the Health Insurance Card Scheme (HICS) managed by the Ministry of Public Health (MOPH) is the key option for migrant workers. However, some migrants are still left uninsured. The likely explanations are the semi-voluntary nature of the HICS, administrative delay of the enrollment process, and the resistance of some employers to hiring migrants.

Conclusions Effective communication is required to raise awareness and acceptance towards the insurance among migrants and their employers. This needs cohesive effort from all stakeholders in society including the government, the business sector, civic groups, and even migrant communities. A public policy participatory process is needed to create a good balance of migrant policies among diverse authorities.

\section{Background}

Globally in 2018 there were about 258 million international migrants and approximately $60 \%$ were migrant workers who travelled abroad to address labour shortages in destination countries [1,2]. The rise of cross-border migrants worldwide attracted political attention as reflected in the number of high-level dialogues and commitments. For example, the 2030 Sustainable Development Goals emphasized the inclusiveness of health among all populations, leaving no one behind [3]. The health of migrants and refugees was specifically raised in the 2017 World Health Assembly (WHA) Resolution 70.15, 'Promoting the Health of Refugees and Migrants' [4]. According to this Resolution, Member States are urged to 
strengthen international cooperation regarding the health of refugees and migrants [5]. A provision for necessary health-related assistance through bilateral and international cooperation was recommended for countries with a high influx of refugees and migrants. In addition, a situation analysis about best practices and lessons learned in various contexts was requested as part of the Global Action Plan on the health of refugees and migrants stipulated in the Seventy-second WHA in 2019 [4].

Thailand has been a popular destination for migrant workers in the Southeast Asia Region for many years. The majority of immigrants travel from neighbouring countries, especially Cambodia, Lao PDR, and Myanmar (CLM) [6]. In 2018, the number of migrants in Thailand was approximately three to four million, and about one and a half million crossed the border without a valid passport or travel pass and were recognised as undocumented migrants [7]. As there is a concern about national security, the Thai government established the One Stop Service (OSS) and the Management Center for Migrant Workers (MCMW) as a mechanism to legalise the undocumented migrant workers. The role of both authorities is to record personal data, coordinate with the health sector for health examinations, and work with the Ministry of Interior (MOI) to issue legitimate residence permits and cooperate with the Ministry of Labour $(\mathrm{MOL})$ to issue work permits. All of these functions are known as the nationality verification (NV) process. In terms of health protection, public health insurance for migrants is one of the most important areas of social policies in Thailand. Overall, the Thai government has implemented two main insurance schemes. The first is the Social Security Scheme (SSS) which covers formal sector workers regardless of their nationality (Thai nationals in the formal sector are also enrolled in the SSS). Migrant workers in formal sector, in theory, need to be insured; the SSS is a compulsory insurance scheme that regulates employers to contribute to a payroll tax, which is equally shared by their employees. The scheme is financed by tripartite contributions. Migrant workers need to pay $5 \%$ of their income to the SSS fund, with employers' subsidies at $5 \%$ and the Thai government's at 2.75\% [8]. The second scheme is the Health Insurance Card Scheme (HICS), regulated by the Division of Health Economics and Health Security (DHEHS) at the Thai Ministry of Public Health (MOPH). The HICS covers migrant workers in the informal sector from CLM nations [9].

Despite the existence of the NV process and public health insurance schemes for migrants, challenges remain. For instance, the MOL reported in 2018 that about 800,000 out of 2 million migrants registered for the NV could not complete the process within the specified timeframe [10]. In reality, there remain migrants (an unknown figure) that have not joined the NV process as intended by the government. Suphanchaimat et al [9] describe these challenges in relation to numerous factors such as ignorance of policies among migrants and employers, a swift change of policies due to both international and domestic pressures, and incoherence of policy direction among concerned authorities. However, none of the work has been addressed the problem of migrant workers accessing the public health insurance schemes.

To unpack these challenges, a thorough understanding of all migrant health policies (including the NV process, the issuance of work permits and insurance measures) and how these policies interact with each other is necessary. This point is the main objective of this study. To address this, we opted to apply a 
systems science approach, which is a useful technique to help illuminate the function of and the interaction of components in a complex system based on mutual engagement of relevant stakeholders[11]. It should be noted that the main focus of this study was migrant enrollment in public health insurance schemes (SSS and HICS).

\section{Methods}

\section{Study design and data collection}

This study applied a qualitative approach based on the concepts of systems dynamics and group model building (GMB) $[12,13]$ The GMB is a participatory process that engages diverse key informants who have expertise in the field and are able to provide insightful comments in a problem statement, model formulation, model conceptualization, and model analysis $[13,14]$. It has advantages as it allows stakeholders to share their mental models on the topic $[15,16]$, which can minimize bias from researchers who may dominate the discussion in other approaches. Two rounds of GMB workshops were arranged with different groups of participants. Each workshop last 150-180 minutes and was organised at the office of the International Policy Program (IHPP), MOPH. The GMB facilitating team comprised three senior modelers, one junior modeler, two gatekeepers and two rapporteurs. Almost all of the facilitators were academic staff of IHPP; only one facilitator was an independent academic expert invited from outside IHPP.

Participants in the GMBs were purposively selected. Participants who had extensive experience in dealing with CLM migrants, either as a policy implementer, a policy advocate, or a policy formulator, were the focus of this study. More specifically, diverse groups of health staff from frontline health professionals to representatives from the $\mathrm{MOPH}$, were included in the GMBs. Experts from the $\mathrm{MOL}$ and the $\mathrm{MOI}$ also participated along with representatives from Non-Government Organizations (NGOs), academia, and independent health system research agencies in Thailand.

\section{Group process}

In each round of GMBs, the process started with an overview presentation of the situation of migrant health in Thailand with a focus on the migrant journey towards obtaining health insurance. The scope of discussion was limited to low-skilled workers from CLM countries. Highly-skilled professionals, expatriates, tourists, asylum seekers and refugees were excluded. The discussion then delved into the two main insurance arrangements of the SSS and HICS. At the end of each session, participants were asked to identify leverage points that critically determined migrant access to health insurance. Leverages are considered to be any factor where its change can have a substantial impact on the whole system [17]. All discussions were led and run by the participants with minimal interference from the facilitators. The facilitators only guided some discussions when necessary in order to make the process run smoothly. The description of participants' profiles is presented later in the Results Section. 
During the group process, the participants were asked to share ideas of the draft CLD. The CLD demonstrates associations among factors relating to insurance enrollment in a cause-and-effect manner. The facilitators drew the CLD on a flipchart based on input from the participants. The research team explained the draft CLD to participants using lay language, and then asked the participants to specify whether a concerned variable exhibited positive (+) or negative (-) influences on other variables. Another key feature in the CLD is a feedback loop which occurs when the effects of consequences have returned to influence the causes [18]. There are two types of feedback loops including reinforcing and balancing. Reinforcing loops indicate that influences of variables in the same loop are travelling in the same direction, whereas balancing loops show travel in opposite directions occurring in the variable relationship. As well as the CLD, the authors also developed SFD to be able to identify the dynamics of the HICS enrollment. The SFD is part of system dynamics, which consists of stocks (the rectangular shapes) and flows (the thick arrows). The stocks indicate accumulation of anything which can be quantified and changed over time. The flows show the direction of change occurring from any stocks which can be inflows or outflows. The CLD and SFD were shown as a qualitative structure to illustrate the relationship of drivers with directions in the system [19]. Then, the research team translated the CLD and SFD from the flipchart to the electronic format by Vensim software [20].

\section{Data analysis}

Data were analysed by deductive-coding thematic analysis. All of the discussions and interviews were transcribed verbatim and then manually coded in an Excel programme. The findings were narratively synthesised as inputs for developing CLD and SFD with reviewed literature as part of triangulation. Important variables were listed in the CLD and SFD with identified connections and directions. The products of thematic analysis are shown in the results section. After that, insights from emerging themes were again mapped and synthesised in the form of CLD and SFD as presented in the discussion section.

\section{Ethics consideration}

Ethics approval was obtained from the Institute for the Development of Human Research Protections in Thailand (IHRP 340/2562). All participants were asked to sign a consent form. The research team assured the participants that their practices were on a voluntary basis and if they felt uncomfortable about participating in the discussions or interviews, they could drop out these activities. Anonymity was protected by coding individual identification numbers instead of noting individual names.

\section{Results}

\section{Characteristics of stakeholders}

The majority of stakeholders were aged 40 years and older. About two thirds of participants were women. One third of participants had been working for more than 30 years. Over half of the participants were at senior professional level. About half of the participants were from the health sector. Approximately $40 \%$ of the attendees were from civic organizations. 
Table 1 Socio-demographic characteristics of stakeholders engaging in the $1^{\text {st }}$ and $2^{\text {nd }} \mathrm{GMB}$

\begin{tabular}{|c|c|c|}
\hline Variable & Category & $\mathrm{N}$ (percentage) \\
\hline \multirow[t]{3}{*}{ Age (years) } & $21-30$ & $5(25)$ \\
\hline & $31-40$ & $5(25)$ \\
\hline & $40+$ & $10(50)$ \\
\hline \multirow[t]{2}{*}{ Sex } & Male & $7(35)$ \\
\hline & Female & $13(65)$ \\
\hline \multirow[t]{4}{*}{ Experience in the field of migrants' health } & $<10$ & $10(50)$ \\
\hline & $10-19$ & $2(10)$ \\
\hline & $20-29$ & $2(10)$ \\
\hline & $>=30$ & $6(30)$ \\
\hline \multirow[t]{3}{*}{ Career level } & Coordinator & $2(10)$ \\
\hline & Middle & $8(40)$ \\
\hline & Senior & $10(50)$ \\
\hline \multirow[t]{5}{*}{ Organization } & Government authority & \\
\hline & Health sector & $10(50)$ \\
\hline & Non-health sector & $1(5)$ \\
\hline & Civil society & $8(40)$ \\
\hline & Academic sector & $1(5)$ \\
\hline Total & & $20(100)$ \\
\hline
\end{tabular}

\section{Key important themes identified from the GBMs}

Five themes emerged from the GBMs: (i) NV process; the most critical step for legalising the precarious status of undocumented migrants; (ii) Interim period between enrollment in the SSS and the effective activation of insurance; (iii) Role of private hospitals in health examination before enrolling in the insurance; (iv) Practical problems originating from the difference in design between the SSS and the HICS; and (v) Data recording system of the HICS.

(i) NV process; the most critical step for legalising the precarious status of undocumented migrants 
From the participants' point of view, the NV process is the most critical step to determine whether an undocumented migrant will be insured as part of the government's registration process, the OSS. The OSS is the official mechanism based on multi-sectoral collaboration across five ministries: (i) Department of Provincial Administration, the MOI of Thailand; (ii) Department of Employment, the MOL of Thailand; (iii) Immigration Bureau, the MOI of Thailand; (iv) the Social Security Office (SSO), the MOL of Thailand; and (v) the MOPH of Thailand. Once registered, the Provincial Administration Office collects the personal records of migrants with evidence of fingerprints. Then the registered migrant is given an identity card (pink-card) with a unique identity number printed on it (13-digit code). The Department of Employment then issues a work permit once the 13-digit code is confirmed. The registered migrants obtain a temporary passport and work visa by the Immigration Bureau. If a migrant is registered to work in the formal sector, he or she will be enrolled in the SSS run by the SSO. The SSS guarantees rights for medical services for all health-related conditions. Those working in the informal sector will be covered by the HICS, run by the MOPH.

The alternative national verification office is the MCMW [10]. This centre is located along the border of the migrants' countries of origin. The chief executive officer is assigned by the deputy director of the MOL, Thailand. The mission of the MCMW is to coordinate with the provincial Labour office or the Bangkok Labour office to facilitate the $\mathrm{NV}$ and registration of personal records within an agreed timeframe. Furthermore, the MCWM gives feedback on challenges experienced during the process of NV to the deputy director of the MOL, Thailand in order to improve the quality of the service.

Once the NV is approved, the now documented migrants will be eligible to lawfully stay in Thailand for a certain time period (normally two years). The proof of evidence of completing the $\mathrm{NV}$ is a temporary passport or visa. If a migrant has not completed the NV, he or she will only receive the pink card as evidence of entering the legalisation process. This card shows information about employers and types of work the migrant is able to do. However, some participants said that there were some misunderstandings about the policy and not all government officers were knowledgeable about the NV process. Some officials still considered migrants holding the pink card to be illegal. This is one of the barriers which prevents migrants from accessing social security benefits, including health insurance.

"After the NV, migrants are legalized as they own a passport and a pink card. Information about each person is later identified in the civil registration section (CVS). While they are waiting for their name to be listed in the CVS, some government officers think that they are still illegal. And they also think that having a pink card refers to illegal status." - Male participant, NGO

\section{(ii) Interim period between enrollment in the SSS and effective activation of insurance}

In principle, once enrolled in the SSS, there is a 90-day interim period until the insurance is activated. The migrants' employers and the migrants are obliged to contribute to the payroll for 90 days until the right to the SSS insurance is activated. Therefore, during the 90-day uninsured period, the HICS is an option for insuring migrants. Although in principle the HICS is set for informal sector migrants, in practice the purchase of the HICS is not that strict and varies across hospitals. The MOPH has initiated many 
subtypes of HICS with varying periods of coverage (for example six-month, one-year, and two-year HICS), Table 2 [9]. About half of the participants emphasised that in the field there were always problems arising among some local health staff that tended to sell the six-month HICS or the one-year HICS to those facing the 90-day SSS-free period. From their viewpoint, this practice happened because the HICS sales mainly depend on the discretion of each individual hospital and some hospitals tended to sell the HICS with extended coverage in order to create a greater pool of revenue. In some circumstances, health staff became active agents in convincing employers to encourage HICS enrollment.

"The six-month or one-year HICS is more favorable than the three-month-HICS as practically a small number of migrant workers will use this right over the 3-month period. The six-month or one-year HICS is a better option because of the longer insured period. Sometimes employers thought that it was not their business (to buy the insurance for migrants) but the hospital insists (that migrants need to be insured by the HICS). The SSO also is not sure if after the three months the employers follow up the SSS for their employees again. It seems this mission (insuring) is not the responsibility of other ministries but of the $M O P H^{\prime \prime}$. - Female participant, public health officer

Table 2 The Health Insurance Card Scheme for migrants and dependents 
Beneficiaries Migrants workers in formal sector

Governing The SSO under the MOL of Thailand body

Financing mechanism,

Tri-partite contribution

Migrant workers aged 18 years and over who need to pay for $5 \%$ of their income to the SSS fund with subsidies of employers at $5 \%$ and Thai government at $2.75 \%$.

Coverage duration
Annual benefit coverage for medical expenses is valid if 3-consecutive payment is done.
Migrant workers in informal sector, illegal migrants, migrant dependents

The Health Insurance Group (HIG) under the MOPH of Thailand

Premium-based financing

The majority of revenues are pooled at the central MOPH and then decentralized to the local health facilities.

1. Migrant aged 18 years and over

- 2,100 Baht (500 Baht for health check $+1,600$ Baht for health insurance) for 1 year

1,400 Baht (500 Baht for health check+900 Baht for health insurance) for 6 months

- 1,000 Baht (500 Baht for health check+ 500 Baht for health insurance) ** Reserved for migrant workers in formal sector during the interim period of official approval from SSO for 3 months

2. Dependents aged 7 years and over but not more than 18 years

- 2,100 Baht (500 Baht for health check $+1,600$ Baht for health insurance) for 1 year

- 1,400 Baht (500 Baht for health check+900 Baht for health insurance) for 6 months

1,000 Baht (500 Baht for health check+ 500 Baht for health insurance) for 3 months

3. Dependents aged not over than 7 years

730 Baht (No health check fee +730 Baht for health insurance) for 2 years

365 Baht (No health check fee +365 Baht for health insurance) for 1 year 
Contract Contract model with the National Health facilities for health check and health insurance

Security Office (NHSO):

Public hospitals (district and provincial hospitals) under the MOPH in the catchment area. Some were not under the MOPH but contracted with the programme of migrant health insurance. Private hospitals in the catchment area.

\section{Benefit}

package

\section{Comprehensive:}

Outpatient, inpatient, accident and emergency, high-cost care;

Compensation at $50 \%$ of migrants' income will be paid for hospital admission. This budget is under the workmen's compensation fund for occupational injuries.
Contract model with the NHSO:

Public hospitals (district and provincial hospitals) under the MOPH in the catchment area. Some were not under the MOPH but contracted with the programme of migrant health insurance.

Private hospitals in the catchment area.

Outpatient, inpatient, health promotion, disease prevention services (including HIV/AIDS treatment, and other high-cost care; excluding renal replacement therapy for chronic renal failure and treatment for psychosis and drug dependence)

Source: Modified from Suphanchaimat et al. [9] and Division of Health Economics and Health security, Ministry of Public Health, Thailand (2019) [21]

\section{(iii) Role of private hospitals in health examination before enrolling in the insurance}

The participants said that, in the field, there were conflicting ideas as to whether and to what extent private facilities could take part in the health check for migrants before these migrants are enrolled in the insurance. This is because one of the pre-conditions for a migrant to obtain a work permit is to pass a health check, which screens for serious communicable diseases such as tuberculosis, filariasis and elephantitis [21]. The problem raised by the participants was that the MOL regulation allows either a private hospital or public hospital (with certified standards as approved by the Hospital Accreditation [HA] System, or the Joint Commission International [JCI] or International Standardization Organization [ISO]) to be responsible for the health check. However, almost all the contracted facilities of the HICS and the SSS are state run and the MOPH regulation does not specify that the hospital performing the health check must be the same hospital that provides the HICS. This approach creates some problems as the majority of private health facilities do not sell health insurance. Therefore, migrants gain the approval of the health check from such facilities but most of them did not continue to buy HICS normally sold by public hospitals elsewhere in the area.

Moreover, some MOL local officers denied the result of the health check particularly from private hospitals, as mentioned by the respondents. 
"The problem is that migrants just went to private hospitals for their health check approval. Many of them do not go further to buy HICS at public hospitals near their workplace. Moreover, some providers perceived that the health check result from a private hospital is invalid (and did not allow migrants to buy the HICS further)." - Female participant, public health officer

Some participants stated that some provinces established an internal agreement among the health facilities within the province that only migrants passing the health exam from public facilities would be eligible to purchase the HICS. Some solutions were suggested by the participants. One participant suggested that the HICS regulation should be amended and this needs to be approved by the Cabinet.

"We communicated within our province to accept only those health check results from public hospitals and declined others from private hospitals or clinics." - Female participant, public health officer

"We need a legal approach to tackle this challenge by revising the law and we need to propose this issue to the Cabinet. The Royal Decree for Health Examination and Health Insurance for Obtaining Work Permit at the status quo (that allows private hospitals to make out a medical certificate) should be cancelled." Male participant, NGO

\section{(iv) Practical problems originating from the difference in the design between the SSS and the HICS}

Most participants pointed to the problems involved with the difference in the payment methods between the SSS and the HICS. One of the common concerns was that some employers and migrant employees were not willing to have their salary deducted as a payroll contribution. In contrast, the purchase of the HICS is a lump sum payment once a year (or in two years according to HICS subtypes). Another problem raised was the legal basis of the HICS and the SSS. The SSS was established according to the Social Security Act 2010 [22], while the HICS was based on the Ministerial Announcement. The Act has a greater hierarchy within the law with a penalty specified for those breaching the law; but this does not apply to the Announcement.

"Some migrants declined to buy HICS once they came into Thailand. This is because there is no mandate that forces migrants to buy HICS" - Male participant, NGO.

This problem was aggravated during transition of job types when a migrant shifts jobs from the formal to informal sector. As mentioned, migrants in the informal sector are obliged theoretically to be insured by HICS, but without any penalty inflicted the enforcement of HICS enrollment is not that strict. Participants mentioned that apart from cost, the fear of being penalized was among key reasons that made migrants avoid government registration (which then resulted in missed opportunities to be insured with either the SSS or the HICS).

"If they have already paid for the SSS subsidy and if they later leave the job then they have to go for HICS." - Male participant, NGO 
"The SSS has advantage (over the HICS) because of the existence of the supporting law. If the employers do not follow this rule, there is no doubt that they will face a penalty. However, practically, some employers avoid this rule and leave their workers uninsured (either with the SSS or the HICS)." - Male participant, NGO

\section{(v) Data recording system of the HICS}

Most participants mentioned the poor management of the HICS reporting system. The MOPH did not report publicly how many migrants were insured with the HICS or the breakdown of the characteristics of the insurees (for example, in terms of sex, age, and occupation).

"The problem is that the number of HICS sales should be publicly reported in the database of the Division of Economics and Health Financing, Ministry of Public Health. But now it seems we can't track which group buys HICS the most and how many HICS are sold. This results in difficulty to monitor and evaluate HICS progress." - Male participant, NGO

Some informants said that it is difficult to report these numbers, as many health facilities are hesitant to report exact HICS revenues to the MOPH. According to the regulation on HICS financing, part of the HICS revenues should be pooled at the MOPH so it can allocate funding back to local health facilities upon requests for reimbursement for high-cost treatment [9]. However, in practice, some health facilities ignored this measure as they were willing to bear the risk of high-cost treatment themselves. This situation is more pronounced in health facilities with a high density of migrant workers, while in some settings with a small number of migrants health facilities are more likely to report this number to minimize financial risk when facing high-cost patients.

"The MOPH can't exactly analyse the number of HICS sales as they don't know how to track this number accurately. Some hospitals feel uncomfortable with reporting HICS revenue to the MOPH as they are willing to take the risk of treatment cost for migrants. If you have about 100 migrant patients, I suppose you tend to report the revenue of HICS to the central MOPH, as it just a small number. In contrast, if you earn 5-7 million Baht from HICS, you won't give this number to the MOPH because if you spend only 700 thousand Baht on treatment, the rest becomes your profit."- Female participant, Public health officer

\section{Discussion}

\section{Result discussion: dynamics of access to health insurance of migrants}

All participants were asked to share their knowledge, views, and experience about factors that determine access to health insurance of undocumented migrants and the dynamics and interaction among those factors as demonstrated in Fig. 1. It is clear that the high demand for, in particular, the '3D' jobs (dangerous, dirty, and demeaning) to address economic necessity is the main factor that drives a high influx of migrant workers $[9,21,23]$. Migrants with illegal status might opt to enter Thailand first then 
undertake the NV later in order to obtain a legalized work permit [9] (as shown in the cloud symbol on the left hand-side of the Fig. 1).

Addressing the illegal status of migrants is not straightforward. Some participants referred to the 20-year National Strategy Plan (2018-2037) which emphasizes the protection of national security [24]; that is illegal migrants need to be deported. However, in reality deportation measures are not always exercised as the government needs to take into account the balance of the demand for labour [25]. The NV and the issuance of a work permit therefore serves as a compromised measure that takes into account the need to balance national security and economic demand. However, as mentioned by participants, implementation of the NV is not perfect. There are always employers who do not take their migrant employees to undertake the OSS registration and delays to NV is caused by incoherence of inter-sectoral policies and poor coordination among relevant ministries.

The dynamics of migrants in the labour market is remarkable [9]. Not all registered migrants are in the labour market all the time. Some might leave the labour system due to personal difficulties, work injuries or financial hardship. The private sector has a dominant role in maintaining the labour flow and has strong power to influence the demand for labour, which includes both documented and undocumented migrant workers $[26,27]$. As the minimum wage in Thailand is higher than that in neighboring countries, Thailand is an attractive destination that provides better job prospects for cross-border migrants. From 1 st of January 2020, any workers in the central area will be paid the minimum wage of 331 Baht (10.7 USD) regardless of their nationality [28]. However, some participants mentioned that the process to enter the country lawfully is complicated and migrants with low educational backgrounds or poor economic status find it difficult. As such, undocumented migrants avoid lawful border-crossing mechanisms [26].

It is clear that migrant workers in the formal sector can enter the SSS scheme with legal binding. Therefore, the decision of employers in SSS enrollment is key to encourage or discourage migrant employees towards insurance. The perception of law enforcement and whether employers can afford to subsidize the SSS are significant factors to maintain migrant workers in the system. All migrants excluded from the SSS theoretically should be insured with the HICS. This group includes undocumented migrants or registered migrants whose nationality verification is not yet complete [9].

As the HICS does not have any penalty, participants agreed that the enrollment of migrant workers in the HICS depended on the discretion of each individual migrant to purchase the insurance (demand side) plus the willingness of health care providers to sell the HICS (supply side). The CLD in Fig. 2 illustrates this idea about supply- and demand-side factors that likely to determine HICS access. On the demand side, the likelihood of migrants buying HICS is shaped by affordability of the insurance, knowledge and awareness about health rights among migrants, and their own health status. Migrants who have not developed any serious diseases are less likely to understand the benefits of being insured. One participant mentioned that in some provinces there was a training course for migrants about basic rights and benefits of the insurance. Additionally, perception of human rights and knowledge of health insurance for migrant workers among employers can also influence HICS enrollment. 
The legal status of a migrant is also a significant determinant that influences access to health insurance [29]. This is because if those with illegal or undocumented status fail to register with the OSS, they are likely to keep themselves uninsured due to fear of deportation if they do expose themselves to authorities. Regarding the economic aspect, the likelihood of the HICS purchasing is negatively associated with the HICS premium as shown in the balancing loop in the CLD.

From a supply-side perspective, the HICS can be a revenue generator for a hospital, especially where the insurees are greater in number. The revenues from selling HICS can help a hospital's financial status and means financial security of the central MOPH. This relationship can be seen in the reinforcing loop (R1). Furthermore, the linkage between HICS and public health security can be observed as an accelerator to the likelihood of the HICS selling. The concern over spreading certain infectious diseases from migrants to the wider Thai public (such as tuberculosis, HIV, syphilis and malaria) that could cause public health threats is a major factor which encourages providers to sell the HICS [30-35]. As a result, the relationship in access to the HICS and public health security is positive as shown in R2 in the CLD. In addition, NGOs and civil society from domestic and international organisations also play an active role in coordinating with government departments, employers, and employees to build trust and advocate social programmes related to human right and health in migrant communities [27]. Accordingly, these local and international movements can create positive feedback to the HICS enrollment system.

At the end of the session, stakeholders discussed leverage points and change that can contribute significantly to the whole system. The majority of the participants concurred that nationality verification and the issuance of work permits are the most important steps that will lead to the uptake of insurance. The government in collaboration with all partners in society should play an active role in bringing all migrants to undertake the NV and register for a work permit. Accordingly, all undocumented migrants should be enforced legally to undertake NV and be insured through either the HICS or the SSS. Strict law enforcement is key. Employers who leave their migrant employees uninsured should be penalized. Support from the government and social partners for migrants who are unable to afford the insurance price should be in place.

\section{Notes}

HICS = Health Insurance Card Scheme; SSS = Social Security Scheme

\section{Notes}

OOP = Out-of-pocket

\section{Methodological Discussion}

To the best of our knowledge, this is the first study to apply a systems thinking approach in understanding the dynamics of access to health insurance among migrants in Thailand. The findings clearly prove that the existence of migrant insurance policy is not in itself a guarantee for access to 
insurance among migrants. To boost migrant access to insurance, synergistic efforts are required from all stakeholders, including the government, employers of migrants, and migrant communities. Increasing awareness of the insurance among migrants and employers, strict law enforcement and seamless intersectoral policies are needed.

However, some limitations exist within the study. First, the process at this stage did not include migrants as participants. Further work that incorporates views of migrants as an insurance beneficiary will definitely provide additional insights. Second, there are groups of non-Thai populations unmentioned here including but not limited to, stateless people, expatriates and refugees. Therefore, the interpretation of the findings to other non-Thai populations must be exercised with caution because each group of non-Thai populations has its own characteristics and face idiosyncratic challenges. Third, access to insurance does not necessarily mean access to care, let alone a better health outcome. There are many factors that influence access to care and the quality of care received. These include adequate supply of health resources, the quality of the services provided, and the underlying health status of the clients (migrants), to name but a few. Further research that explores the angles of healthcare access and health outcomes is recommended.

\section{Conclusion}

With the GMB and the CLD, it is clear that the access to public health insurance among migrants in Thailand is a complex matter. The existence of insurance itself is not a standalone measure. In fact, the issue is deeply involved and interplays with the concept of economic necessity and national security. It is inextricably linked with many other measures that are not the mandate of the health sector, particularly the NV process and the issuance of a work permit. The HICS and the SSS are the key health insurance schemes for migrants in Thailand. Both are publicly run but are different in payment mechanism designs and target beneficiaries. The SSS focuses more on formal-sector employees while the HICS targets the informal-sector employees. Access to health insurance is beneficial for financial protection among the insurees and at the same time partly helps improve the financial status of health facilities. Challenges that hinder access to insurance include poor law enforcement on the employers of migrants, inadequate awareness of the existence of the insurance among migrants, and unaffordability of the insurance premium. The leverage points that potentially contribute to the enrollment in the HICS and the SSS are the NV and the issuance of work permits. The government should be the key player in moving this issue forward while harnessing efforts from diverse social partners. According to this idea, all undocumented migrants should be enforced legally to undertake NV and be insured with the public insurance schemes. Strict law enforcement is the key. The employers who leave their migrant employees uninsured should be penalised. Support from the government and social partners for migrants who are unable to afford the insurance price should be in place.

\section{Abbreviations}

GMB 
Group Model Building; CLD:Causal Loop Diagram; SFD:Stock and Flow Diagram; SSS:Social Security Scheme; MOL:Ministry of Labour; HICS:Health Insurance Card Scheme; MOPH:Ministry of Public Health; WHA:World Health Assembly; CLM:Cambodia, Lao PDR, and Myanmar; OSS:One Stop Service; MCMW:Management Center for Migrant Workers; MOI:Ministry of Interior; NV:Nationality Verification; DHEHS:Division of Health Economics and Health Security; IHPP:International Health Policy Program; NGOs:Non-Government Organizations; HA:Hospital Accreditation; JCl:Joint Commission International; ISO:International Standardization

\section{Declarations}

\section{Acknowledgement}

The authors would like to thank health and non-health professionals who provided insightful comments in the GMB process.

\section{Funding}

The publication fee of this article was supported by the Health Systems Research Institute (HSRI), Thailand

\section{Authors' contributions}

WK, RS, HK, NP and PT conceptualized the study. SJ, MP and PS facilitated all project-related tasks. WK, RS, PT and NP drafted and critically revised the manuscript.

All authors have read and approved the final manuscript.

\section{Competing interest}

The authors declare that they have no competing interests.

\section{Author details}

${ }^{1}$ International Health Policy Program, Ministry of Public Health, Muang, Nonthaburi, Thailand. ${ }^{2}$ Stamford International University, Motorway Road - Km2, Prawet, Bangkok, Thailand. ${ }^{3}$ Bureau of Epidemiology, Department of Disease Control, Ministry of Public Health, Muang, Nonthaburi, Thailand.

\section{References}

1. IOM. Data bulletin series: Informing the Implementation of the Global Compact for Migration . 2018. https://publications.iom.int/system/files/pdf/gmdacbulletins.pdf. Accessed 6 Nov 2019.

2. Wickramage K, Simpson PJ, Abbasi K. Improving the health of migrants. BMJ. 2019;366:I5324. 
3. United Nations. Transforming our World: The 2030 Agenda for Sustainable Development. New York: United Nations; 2015. https://sustainabledevelopment.un.org/sdgs. Accessed 5 Nov 2019.

4. WHO. Promoting the health of refugees and migrants: draft action plan, 2019-2023. Apri 25, 2019. http://apps.who.int/gb/ebwha/pdf_files/WHA72/A72_25-en.pdf. Accessed 6 Nov 2019.

5. UNHCR. The New York Declaration for Refugees and Migrants. 2016. https://www.unhcr.org/584689257.pdf. Accessed 6 Nov 2019.

6. Suphanchaimat R, Pudpong N, Prakongsai P, Putthasri W, Hanefeld J, Mills A. The Devil Is in the Detail-Understanding Divergence between Intention and Implementation of Health Policy for Undocumented Migrants in Thailand. Int J Environ Res Public Health. 2019;16(6):1016.

7. WHO South-East Asia Region. Health of Refugees and Migrants: Parctices in Addressing the Health Needs of Refugees and Migrants. 2018. https://www.who.int/migrants/publications/SEAROPractices.pdf?ua=1. Accessed 6 Nov 2019.

8. Department of Employment. Ministry of Labour of Thailand. Guidelines for Documented Migrant Workers in Thailand. https://bit.ly/2WkFkFC. Accessed 29 Oct 2019.

9. Suphanchaimat R, Putthasri W, Prakongsai P, Tangcharoensathien V. Evolution and complexity of government policies to protect the health of undocumented/illegal migrants in Thailand - the unsolved challenges. Risk Manag Healthc Policy. 2017;10:49-62.

10. Department of Employment. Ministry of Labour of Thailand. Guidelines for the Management of Migrant Workers in Thailand Regarding Cabinet Resolution on 16 Jan B.E. 2561; 2018. https://bit.ly/31UoNJR. Accessed 29 Oct 2019.

11. Petticrew M, Knai C, Thomas J, Rehfuess EA, Noyes J, Gerhardus A, et al. Implications of a complexity perspective for systematic reviews and guideline development in health decision making. BMJ global health. 2019;4(Suppl 1):e000899.

12. Sterman JD. Learning from evidence in a complex world. Am J Public Health. 2006;96(3):505-14.

13. Hovmand PS. Group model building and community-based system dynamics process. Community Based System Dynamics: Springer; 2014. p. 17-30.

14. Andersen DF, Vennix JA, Richardson GP, Rouwette EA. Group model building: problem structuring, policy simulation and decision support. J Oper Res Soc. 2007;58(5):691-4.

15. De Pinho H. Systems Tools for Complex Health Systems: A Guide to Creating Causal Loop Diagrams. Mailman School of Public Health, Columbia University, New York. 2015.

16. Luna-Reyes LF, Martinez-Moyano IJ, Pardo TA, Cresswell AM, Andersen DF, Richardson GP. Anatomy of a group model-building intervention: Building dynamic theory from case study research. Syst Dyn Rev. 2006;22(4):291-320.

17. Rwashana AS, Nakubulwa S, Nakakeeto-Kijjambu M, Adam T. Advancing the application of systems thinking in health: understanding the dynamics of neonatal mortality in Uganda. Health Res Policy Syst. 2014;12(1):36.

18. Bayer S. Business dynamics: systems thinking and modeling for a complex world. JSTOR; 2004. 
19. Mumba C, Skjerve E, Rich M, Rich KM. Application of system dynamics and participatory spatial group model building in animal health: A case study of East Coast Fever interventions in Lundazi and Monze districts of Zambia. PLoS One. 2017;12(12):e0189878.

20. Ventama Systems Inc. Vensim [Software]. 2014. https://vensim.com/vensim-software/. Accessed 28 Oct 2019.

21. Division of Health Economics and Health Security. Notification of the Ministry of Public Health of Thailand Re: Health Examination and Health Insurance for Migrant workers 2019. https://dhes.moph.go.th/?p=4869. Accessed 28 Oct 2019.

22. The Social Security Office. Social Security Act in the Name of His Mejesty King Bhumibol (enacted on the 11 Aug B.E. 2553); 2010. https://bit.ly/2MVAl63. Accessed 29 Oct 2019.

23. Chalamwong Y, Prugsamatz R. Labor Migration in Thailand: Recent Trends and Implications for Development. TDRI Quarterly Review. 2009:3-9.

24. Office of the National Economic and Social Development Council. National Strategic Plan (20182037). https://bit.ly/2Wo6Bac. Accessed 30 October 2019.

25. Ministry of Labour of Thailand. Action Plan for Fiscal Year 2019: Ministry of Labour: 2019. https://bit.ly/323rdpL. Accessed 30 Oct 2019.

26. Thailand Development Research Institute. Although the mamangement of migrant workers is diffucult, how to sustain the success is more ideal. https://bit.ly/36x0CnW. Accessed 6 Jan 2020.

27. Harkins B. Thailand migration report 2019. Bangkok: United Nations Thematic Working Group on Migration in Thailand. 2019.

28. The Committee of the Wage of Thailand. Notification of the Ministry of Labour of Thailand Re: the Minimum Wage (Issue 10). https://bit.ly/2uguelf. Accessed 2 Feb 2020.

29. Chamchan C, Sunpuwan M, Tadee R, Taweesin S. Instituition of Population and Social Science Reserach. The management of the health insurance system and health service provision which is appropriate for migrant labor after the change of migrant labor management policy B.E. 2555 (2012). Nakhon Pathom; 2017.

30. Tangcharoensathien V, Patcharanarumol W. The Political Economy of UHC Reform in Thailand: Lessons for Low- and Middle-Income Countries. Health Syst Reform. 2019;5(3):195-208.

31. Tschirhart N, Nosten F, Foster AM. Migrant tuberculosis patient needs and health system response along the Thailand-Myanmar border. Health Policy Plan. 2017;32(8):1212-9.

32. Musumari PM, Chamchan C. Correlates of HIV Testing Experience among Migrant Workers from Myanmar Residing in Thailand: A Secondary Data Analysis. PLoS One. 2016;11(5):e0154669-e.

33. Tangmunkongvorakul A, Musumari PM. "When I first saw a condom, I was frightened": A qualitative study of sexual behavior, love and life of young cross-border migrants in urban Chiang Mai, Thailand. PloS one. 2017;12(8):e0183255.

34. Parker DM, Carrara VI, Pukrittayakamee S, McGready R, Nosten FH. Malaria ecology along the Thailand-Myanmar border. Malaria journal. 2015;14(1):388. 
35. Carrara VI, Lwin KM, Phyo AP, Ashley E, Wiladphaingern J, Sriprawat K, et al. Malaria burden and artemisinin resistance in the mobile and migrant population on the Thai-Myanmar border, 19992011: an observational study. PLoS medicine. 2013;10(3):e1001398.

\section{Figures}

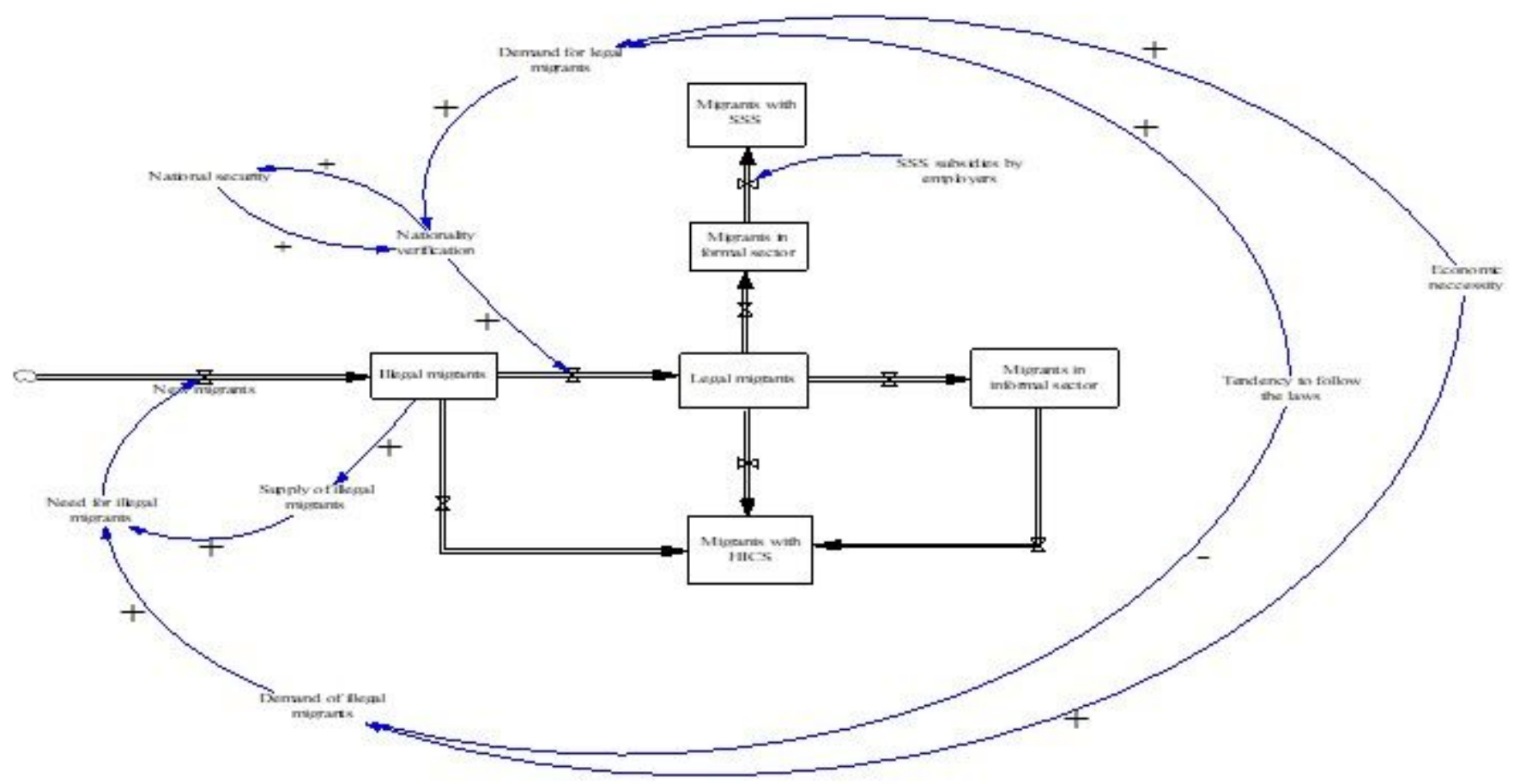

Figure 1

Stock and flow diagramme (SFD) of the dynamics of the legalization process and access to health insurance (SSS and HICS) by migrant workers. Notes: HICS = Health Insurance Card Scheme; SSS = Social Security Scheme 


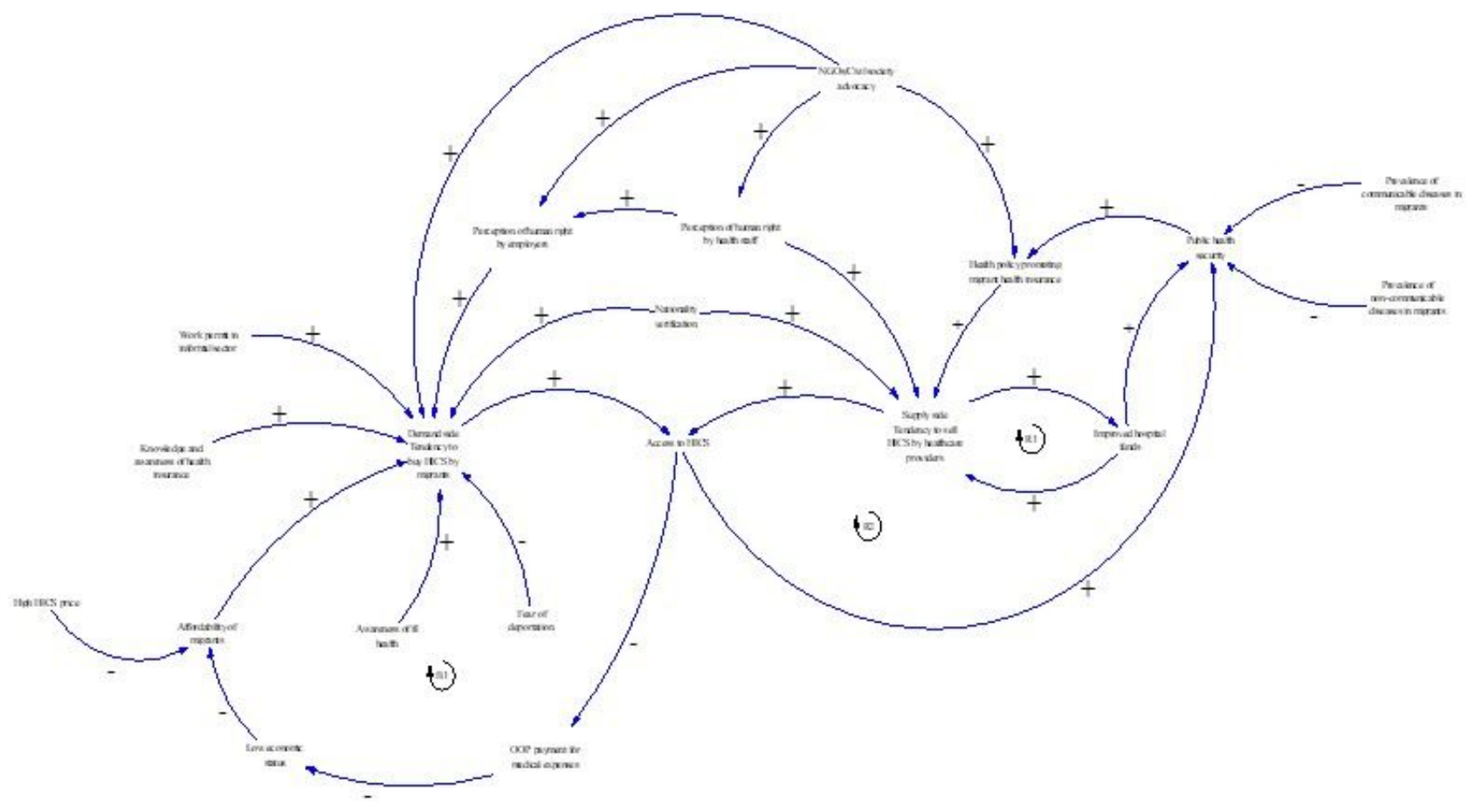

Figure 2

Causal loop diagramme (CLD) of the dynamics of access to health insurance (Health Insurance Card Scheme (HICS)) by migrant workers. Notes: OOP = Out-of-pocket 